\title{
OPEN Asymmetric response of the Indian summer monsoon to positive and negative phases of major tropical climate patterns
}

\begin{abstract}
Arindam Chakraborty ${ }^{1,2,3 \bowtie}$ \& Priyanshi Singhai ${ }^{1,2}$
The existing theories for the tropical teleconnections to Indian summer monsoon (ISM) are diverse in approaches. As a result, it is impossible to quantify the relative impacts of different tropical climate patterns on ISM, complying with a single physical mechanism. Here, we show that tropical teleconnections to ISM can be explained through net moisture convergence driven by surface pressure $(P s)$ gradients surrounding the Indian region. The positive and negative phases of major tropical climate patterns modulate these pressure gradients asymmetrically in the zonal and/or meridional directions leading to asymmetric changes in moisture convergence and ISM rainfall (ISMR). Stronger El Nino droughts than La Nina floods are due to greater decreased eastward moisture flux over the Arabian Sea during El Nino than the corresponding increase during La Nina driven by proportionate meridional Ps gradients. While the equatorial Atlantic Ocean's sea surface temperature in boreal summer and El Nino Southern Oscillation in the preceding winter changes ISMR significantly, moisture convergence anomalies driven by the Indian Ocean Dipole were insignificant. Moreover, while ISMR extremes during ENSO are due to asymmetric changes in zonal and meridional gradients in Ps, nonENSO ISMR extremes arise due to the zonal gradient in zonally symmetric $P s$ anomalies.
\end{abstract}

The Indian summer monsoon exhibits strong interannual variability from bi-annual to multi-decadal time scales $^{1-5}$. These variations are due to external forcings as well as internal variability of the non-linear system ${ }^{6,7}$. Tropical teleconnections such as the El Nino Southern Oscillation (ENSO), the Indian Ocean Dipole (IOD), the tropical Atlantic variability (ATL), and the preceding winter ENSO (W-ENSO) influences ISM rainfall. Such tropical climate patterns modulate large-scale circulation and moist convection over India through various atmosphere-ocean teleconnections ${ }^{8-11}$

The ENSO is the dominant forcing to the ISM that explains about $29 \%$ of its total interannual variability. The El Nino (La Nina) is generally associated with a reduction (increase) in ISMR. ENSO leads to large-scale fluctuation of surface pressure between the Pacific and the Indian Ocean and associated changes in winds and rainfall over India. The warm (cold) phase of ENSO impacts ISM through the eastward (westward) displacement of the Walker circulation ${ }^{12,13}$. ENSO could also impact ISMR through modulating the meridional gradient of uppertropospheric temperature ${ }^{14}$. The change in upper-tropospheric temperature is due to a stationary midlatitude Rossby wave response to equatorial heating ${ }^{15}$. However, the strength of the impact of ENSO on ISMR varies on decadal time scales ${ }^{8,16-18}$, and with future warming scenario ${ }^{19}$. However, the mechanisms mentioned above fail to associate a thermodynamic parameter that is directly liked to moist convection over the Indian region to remote ENSO forcing. For example, velocity potential (a surrogate for Walker circulation) does not correspond well with the precipitation anomaly over the Indian region ${ }^{20}$. Moreover, velocity potential and upper-level temperature gradient itself are a function of convection and are greatly influenced by latent heat release due to convection. On the contrary, several studies demonstrate that the positive and negative phases of ENSO could be asymmetric and its atmospheric response to tropical precipitation ${ }^{21,22}$. Hence, it is essential to understand if the impact of ENSO on ISMR is also asymmetric in nature.

The Indian Ocean Dipole (IOD) and Equatorial Indian Ocean Oscillation impact the ISM by modulating meridional monsoon circulation ${ }^{2,9}$. The positive IOD events tend to intensify rainfall by inducing anomalous

\footnotetext{
${ }^{1}$ Centre for Atmospheric and Oceanic Sciences, Indian Institute of Science, Bengaluru 560012, India. ${ }^{2}$ Divecha Centre for Climate Change, Indian Institute of Science, Bengaluru 560012, India. ${ }^{3}$ DST-Centre of Excellence in Climate Change, Divecha Centre for Climate Change, Indian Institute of Science, Bengaluru 560012, India. ${ }^{\circledR}$ email: arch@iisc.ac.in
} 
(a)

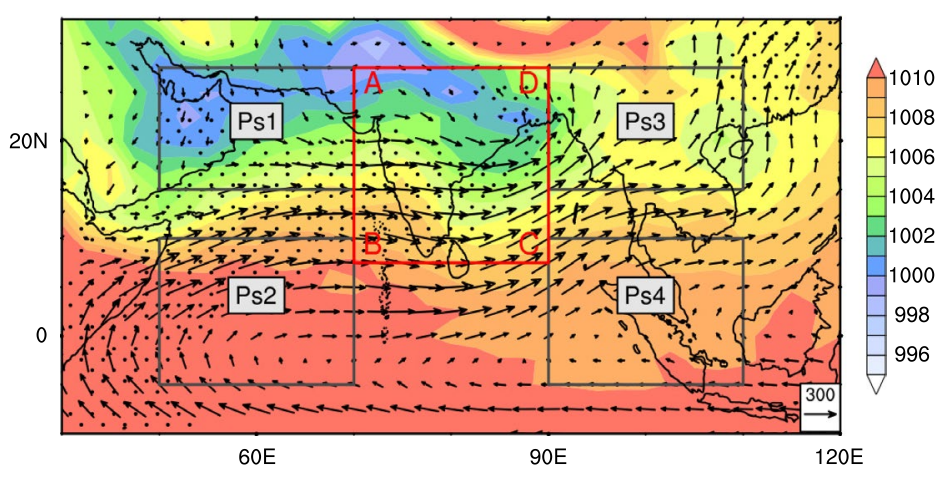

(b)

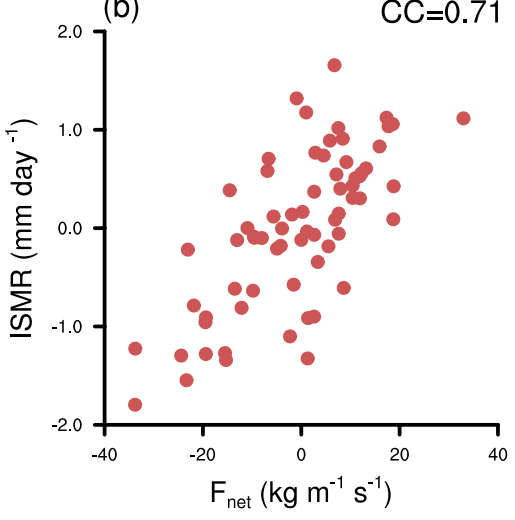

Figure 1. (a) Boreal summer season (June-September) climatological mean sea level pressure (MSLP) in hPa, along with vertically integrated moisture flux vectors $\left(\mathrm{kgm}^{-1} \mathrm{~s}^{-1}\right)$ during the 1948-2015 period. The box ABCD represents the study region $\left(7.5^{\circ}-27.5^{\circ} \mathrm{N}, 70^{\circ}-90^{\circ} \mathrm{E}\right)$. The surrounding boxes represent the regions of surface pressure used for determining the incoming and outgoing moisture fluxes (Ps $1: 15^{\circ}-27.5^{\circ} \mathrm{N}, 50^{\circ}-70^{\circ} \mathrm{E}, P s 2: 5^{\circ}$ $\left.\mathrm{S}-10^{\circ} \mathrm{N}, 50^{\circ}-70^{\circ} \mathrm{E}, P s 3: 15^{\circ}-27.5^{\circ} \mathrm{N}, 90^{\circ}-110^{\circ} \mathrm{E}, P s 4: 5^{\circ} \mathrm{S}-10^{\circ} \mathrm{N}, 90^{\circ}-110^{\circ} \mathrm{E}\right)$. (b) The scatter of Indian summer monsoon rainfall (ISMR, only land points of region $\mathrm{ABCD}$ ) versus net moisture convergence $\left(F_{\text {net }}\right)$ over the entire region marked by ABCD. Inset value is for correlation coefficient (CC) between ISMR and $F_{n e t}$ for 19482015. The dotted regions in Fig. 1a indicate a correlation coefficient between ISMR and $F_{\text {net }}$, which is significant at a $90 \%$ confidence level (using t-test). This figure was created using NCL version 6.4.0 (https://www.ncl.ucar. $\mathrm{edu} /)$.

convergence over the Bay of Bengal and an increase in moisture transport from the southeastern Indian $\mathrm{Ocean}^{23,24}$. A recent study has highlighted the role of moisture transport from the western pole towards the Indian region during positive IOD events ${ }^{25}$. However, the impact of negative IOD on ISMR was shown to be on account of modulation of the northward propagation of convective system ${ }^{26}$. The Indian Ocean Basin Mode and the Central Indian Ocean Mode also play important role in ISM $^{27-29}$. El Nino exerts prolonged influence on the Indian Ocean through the thermal capacitor effect. The continued warming over the tropical Indian Ocean forces a Matsuno-Gill response in the upper troposphere that strengthens south-Asian high, leading to enhanced southwest monsoon ${ }^{27,30}$. In contrast, an opposite cooling effect is not observed during boreal winter La Nina years ${ }^{11}$.

Tropical Atlantic SST variability (ATL) also exhibits an inverse relationship with ISMR similar to that of ENSO $^{31-33}$. A warm tropical Atlantic Ocean forces a Gill-type quadrupole response, with anticyclonic circulation over the Indian and western North Pacific Ocean leading to a decline in ISMR ${ }^{10}$. Anomalous ATL could also modulate the divergence associated with the Asian jet leading to east-west dipole in rainfall over India ${ }^{31}$. The relationship between ATL and ISMR has shown to be strengthened in the recent decades ${ }^{34}$ on account of an enhancement of the Kelvin wave response into the Indian Ocean ${ }^{33}$.

ENSO also exhibits a delayed impact on the Indian and east Asian monsoon ${ }^{11,28,35-37}$. Study of such impact is important from predictability point of view especially with summer ENSO neutral conditions when dominant forcing is weak. For instance, preceding winter La Nina reduce ISMR even during summer ENSO neutral years ${ }^{11}$. This is due to the zonal propagation of surface pressure anomalies from winter to summer, which impacts moisture transport over the Arabian Sea and Bay of Bengal. Moreover, the response of ISMR to the ENSO transition from preceding winter to summer is not symmetric.

In summary, we note that there exist various theories explaining the tropical teleconnection to the ISM. However, they are diverse in their approaches. As a result, it is impossible to quantify the relative impacts of these tropical climate patterns on the ISM. A common theory would be helpful not only in unravelling the relative impacts of different oceans basins, but also to diagnose numerical models deployed for prediction.

Water vapour is the primary driver for atmospheric moist convection. Water vapour played a major role for the increase of the ISM during the deglacial period ${ }^{38}$. The seasonal variation of rainfall over India can also be explained by the seasonal variation of total column water vapour in the atmosphere ${ }^{39,40}$. The net moisture convergence over the Indian region is primarily driven by the balance between the incoming and outgoing fluxes of moisture through the strong lower atmospheric winds. Thus, it is imperative to understand what drives the largescale circulation and moisture transport relating to the year-to-year variations of the Indian summer monsoon.

\section{Results}

The mean sea-level pressure (MSLP) over the south and east Asia shows a north-south gradient (Fig. 1a) primarily during boreal summer (June-September). This meridional gradient is particularly prominent through $45^{\circ}-90^{\circ} \mathrm{E}$ with the lowest pressure pronounced over the Gangetic plains of India (the monsoon trough ${ }^{41-43}$ ) extending up to the northern Arabian Sea and the Arabian Peninsula. Climatologically, the north-western parts of India and west-central Asia experience the lowest MSLP. Interannual variations of Ps over this region in the pre-monsoon months modulate the location and strength of low-level winds toward India. Changes in the moisture-laden winds, in turn, play a crucial role in the onset of monsoon over central India ${ }^{44,45}$. 
(a)

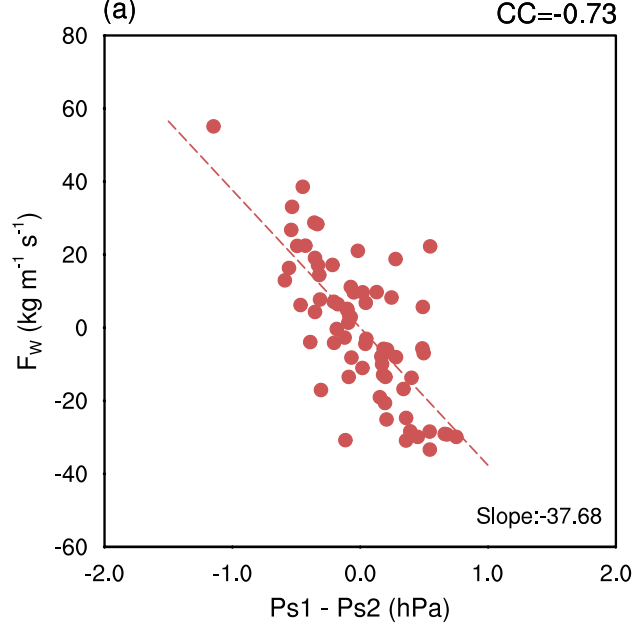

(b)

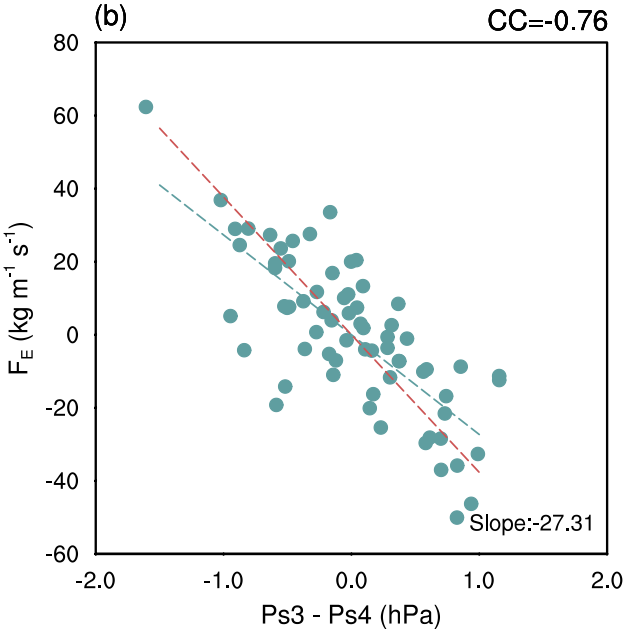

Figure 2. Relation between vertically integrated zonal moisture flux and meridional surface pressure difference. (a) The scatter between vertically integrated moisture flux at the western boundary $\left(F_{W}\right)$ and the surface pressure difference over regions $P s 1\left(15^{\circ}-27.5^{\circ} \mathrm{N}, 50^{\circ}-70^{\circ} \mathrm{E}\right)$ and $P_{s} 2\left(5^{\circ} \mathrm{S}-10^{\circ} \mathrm{N}, 50^{\circ}-70^{\circ} \mathrm{E}\right)$. (b) The scatter of vertically integrated moisture flux along the eastern boundary $\left(F_{E}\right)$ versus surface pressure variations over regions $P_{s} 3\left(15^{\circ}-27.5^{\circ} \mathrm{N}, 90^{\circ}-110^{\circ} \mathrm{E}\right)$ and $P_{s} 4\left(5^{\circ} \mathrm{S}-10^{\circ} \mathrm{N}, 90^{\circ}-110^{\circ} \mathrm{E}\right)$. The correlation coefficient (CC) between zonal moisture flux and surface pressure difference is shown at the top of each panel.The red and blue lines are the least-square fit for the western and eastern boundary, respectively. This figure was created using NCL version 6.4.0 (https://www.ncl.ucar.edu/).

The net convergence of moisture $\left(F_{n e t}\right)$ over the region $\mathrm{ABCD}$ of Fig. 1a is highly correlated with the ISMR (Fig. 1b; correlation coefficient, $C C=0.71$ ). Thus, over a season, the net convergence of moisture over the domain determines the interannual variations of ISMR. We note here that $F_{\text {net }}$ regulates total column water vapour $\left(P_{\text {wat }}\right)$ anomaly (Supplementary Fig. 3a), which in turn is responsible for the interannual variations of ISMR ${ }^{38,39}$ (Supplementary Fig. 3b). The zonal moisture flux through $\mathrm{AB}\left(F_{W}\right)$ and $\mathrm{CD}\left(F_{E}\right)$ far exceed the meridional fluxes through $\mathrm{BC}\left(F_{S}\right)$ and $\mathrm{DA}\left(F_{N}\right)$ (Supplementary Fig. 4). As a result, the balance of zonal fluxes at $\mathrm{AB}$ and $\mathrm{CD}$ dominates the net moisture convergence over the Indian region. A detailed study is thus necessary to unravel the factors determining the interannual variations of these fluxes. However, as we have shown later that the meridional fluxes could also be as important especially during an IOD event. Such findings will help understand global teleconnection to ISM.

Driver for zonal moisture flux: surface pressure or temperature gradient? Suppose we assume geostrophic balance is valid at all layers except very close to the surface (Supplementary Note 1). In that case, the interannual variations of the lower tropospheric zonal winds along the western and eastern boundaries of the Indian monsoon region are driven by the corresponding region's meridional Ps gradients (Supplementary Fig. 2). Encouraged by these results, we plot the vertically integrated moisture flux at the western boundary $\left(F_{W}\right)$ as a function of Ps1 minus Ps2 in Fig. 2a. A strong relationship $(\mathrm{CC}=-0.73)$ between the two parameters confirms that $P_{s}$ variations over regions $P s 1$ and $P_{s} 2$ can be taken as a proxy for the zonal moisture flux at $70^{\circ} \mathrm{E}$. A similar, albeit stronger relationship ( $\mathrm{CC}=-0.76)$ is found for $P s$ difference over $P s 3$ and $P s 4$, and moisture flux along the eastern boundary of the Indian region $\left(90^{\circ} \mathrm{E} ; \mathrm{Fig} .2 \mathrm{~b}\right)$. We note that the correlation coefficient between the meridional $P s$ gradient and moisture flux is stronger along the eastern boundary. However, the change in moisture flux per unit change in meridional $P s$ gradient is stronger along the western boundary (slopes are $-37.7\left(\mathrm{~kg} \mathrm{~m}^{-1} \mathrm{sec}^{-1}\right) / \mathrm{hPa}$ and $-27.3\left(\mathrm{~kg} \mathrm{~m}^{-1} \mathrm{sec}^{-1}\right) / \mathrm{hPa}$ along the west and east boundaries, respectively). We will later observe how tropical climate patterns impact monsoon over India through changes in Ps over these regions.

Tropical teleconnection. El Niño vs La Nina. The most notable increase in Ps during El Nino is over the western parts of India and the northern Arabian Sea, measuring about $1 \mathrm{hPa}$ over a large region (Fig. 3a). The increase in $P s$ over the southern Arabian Sea and the western equatorial Indian Ocean is much weaker than the increase toward its north. Such unequal change in $P_{s}$ weakens its meridional gradient (Supplementary Fig. 5a), decreasing low-level winds and moisture flux. On the other hand, at the eastern side of the Indian region, the meridional $P s$ gradient strengthens in El Nino years (Supplementary Fig. 5b) because of a more significant increase in $P s$ in the south (Maritime continents). Ps anomalies are negative over the western North Pacific Ocean, a typical signature of El Nino condition ${ }^{46,47}$, increasing the eastward moisture flux outward of the Indian monsoon domain.

During La Nina, $P s$ decreases over the northern Arabian Sea and Arabian Peninsula. However, this decrease is not as substantial as the increase in $P$ s over this region during El Nino (compare Fig. $3 \mathrm{a}$ and b). As a result, the decrease in $F_{W}$ during El Nino is more than the increase in $F_{W}$ during La Nina (3c). On the contrary, the 
(a)

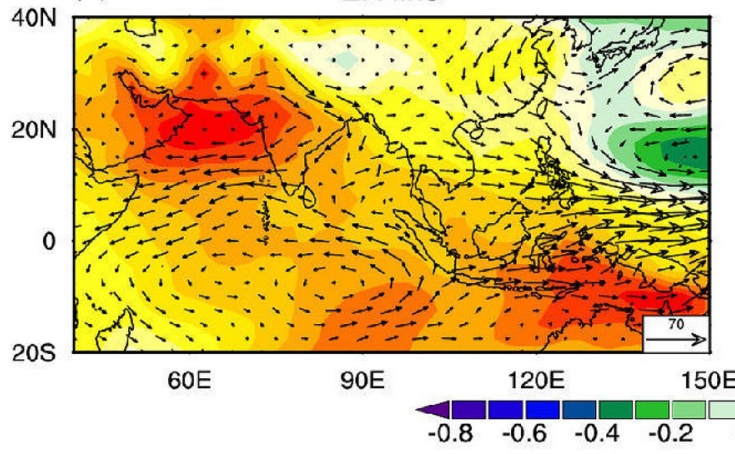

(c)

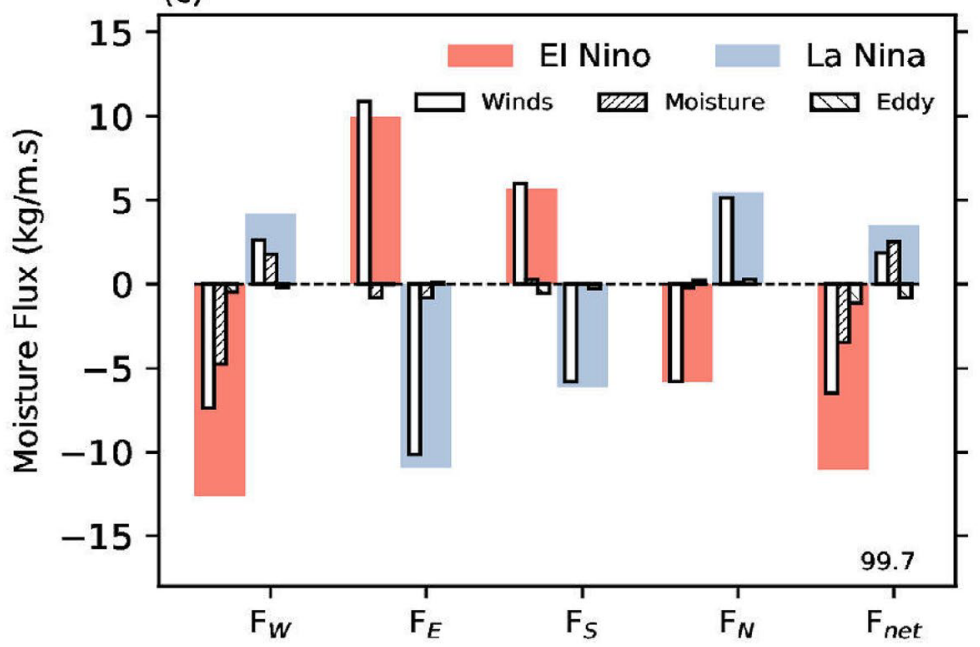

(b)

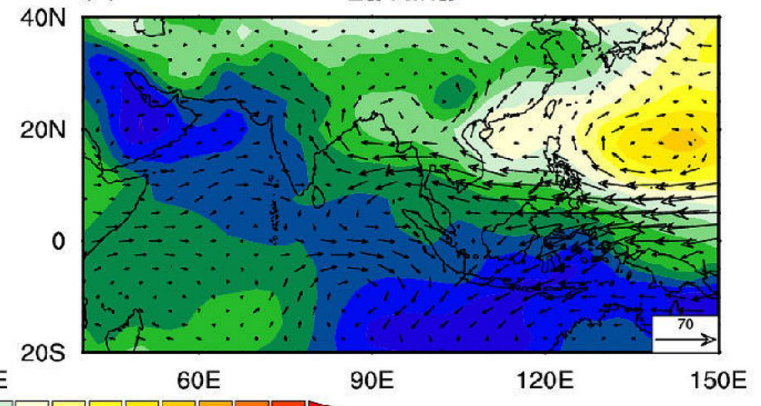

(d)

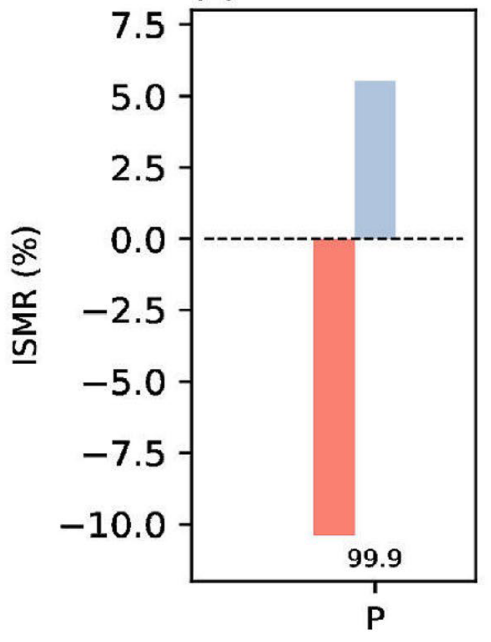

Figure 3. The teleconnection to El Nino Southern Oscillation (ENSO). Composite change in the anomalous surface pressure hPa and vertically integrated moisture flux vector $\left(\mathrm{kgm}^{-1} \mathrm{~s}^{-1}\right)$ during (a) El Nino and (b) La Nina. (c) Shows the vertically integrated moisture flux anomalies and its decomposition along the four boundaries (west $\left(F_{W}\right)$, east $\left(F_{E}\right)$, south $\left(F_{S}\right)$, and north $\left.\left(F_{N}\right)\right)$ and net moisture convergence $\left(F_{\text {net }}\right)$ over region marked as ABCD in Fig. 1a, for El Nino (red) and La Nina (blue) years. The contribution to total moisture flux (solid fill) and its components: due to winds $\left(\left\langle\vec{V}^{\prime} \bar{q}\right\rangle\right)$, moisture $\left(\left\langle\vec{V} q^{\prime}\right\rangle\right)$, and eddy flux $\left(\left\langle\vec{V}^{\prime} q^{\prime}\right\rangle\right)$. (d) The corresponding change in the Indian summer monsoon rainfall (ISMR) during El Nino and La Nina. The number along $F_{\text {net }}$ and $\mathrm{P}$ represents the significance level at which the hypothesis that means are the same for ENSO years is rejected. This figure was created using NCL version 6.4.0 (https://www.ncl.ucar.edu/).

decrease in Ps over the eastern equatorial Indian Ocean and Maritime continents spreads over a larger region than the corresponding increase during El Nino. The increase in $F_{E}$ during El Nino is comparable to the corresponding decrease during La Nina. In other words, while El Nino impacts the moisture flux over the Arabian Sea more than La Nina, both El Nina and La Nina change $F_{E}$ symmetrically but with opposite signs. We also note that the decrease in $F_{n e t}$ during El Nino exceeds the corresponding increase during La Nina, resulting in a more substantial reduction in ISMR during El Nino than the corresponding increase during La Nina (Fig. 3d).

We further decompose the moisture flux into three components to understand the relative contribution from the winds (dynamics) and moisture (thermodynamic) ${ }^{48}$ :

$$
\vec{F}^{\prime}=\langle\vec{V} q\rangle^{\prime}=\left\langle\vec{V}^{\prime} \bar{q}\right\rangle+\left\langle\overline{\vec{V}} q^{\prime}\right\rangle+\left\langle\vec{V}^{\prime} q^{\prime}\right\rangle
$$

where $\langle\cdot\rangle$ represents vertical integral through the depth of the troposphere $\left(\int_{0}^{p_{s}} . d p / g\right)$. The overbar $\left(^{-}\right)$represents climatological values and the prime $\left({ }^{\prime}\right)$ represents anomalies. $F$ is the vertically integrated horizontal moisture flux, and $V$ is the horizontal wind vector. The first (second) term of the above equation represents the contribution of moisture flux anomaly because of change in the wind (moisture). The third term represents anomalous winds acting on anomalous moisture. We found the third term to be negligible compared to the other two terms in our analysis.

The hatched parts of the bars in Fig. $3 \mathrm{c}$ indicate the moisture flux component contributed by the moisture part. Moisture anomalies contribute about $40 \%$ to the total $F_{W}$ during El Nino and La Nina. However, the contribution of moisture to fluxes along the other three boundaries is small. The large contribution of anomalous moisture on $F_{W}$ during El Nino and La Nina possibly indicates the role of moisture feedback in monsoon intensity. For 
(a)

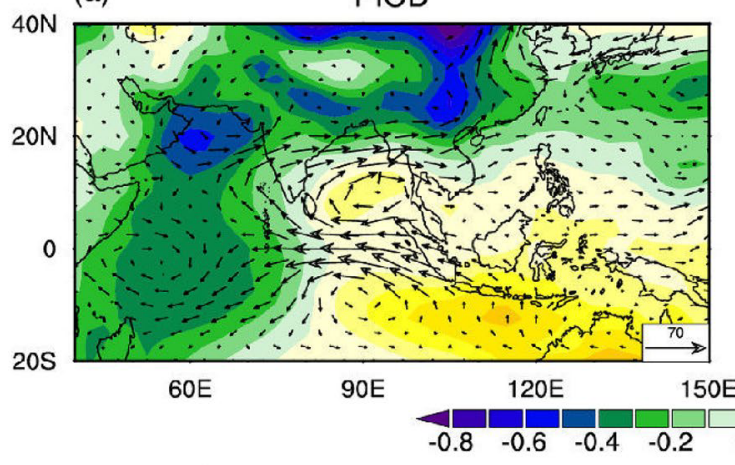

(c)

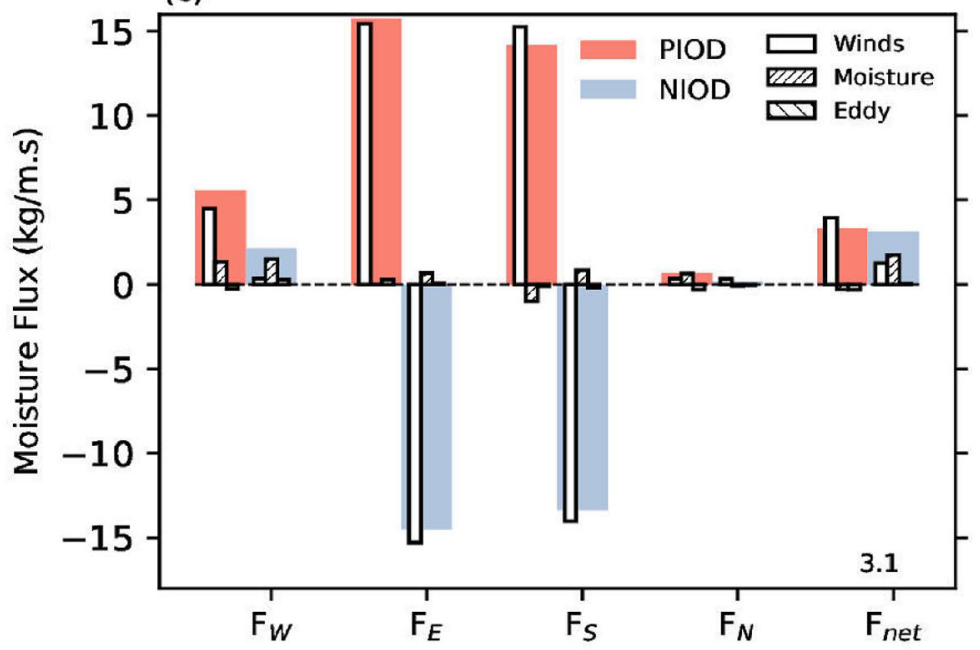

(b)

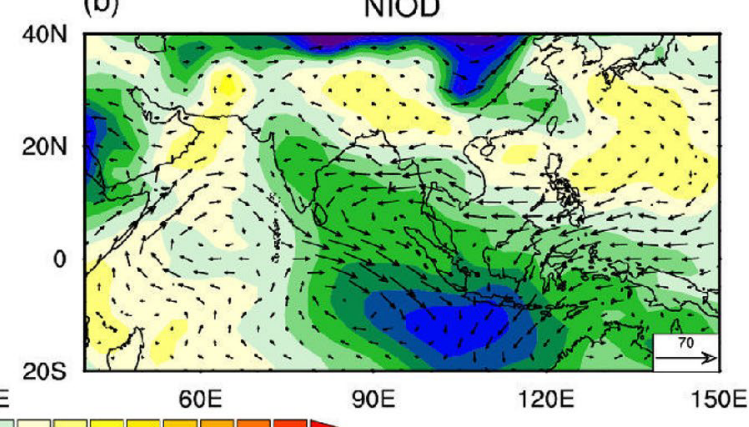

(d)

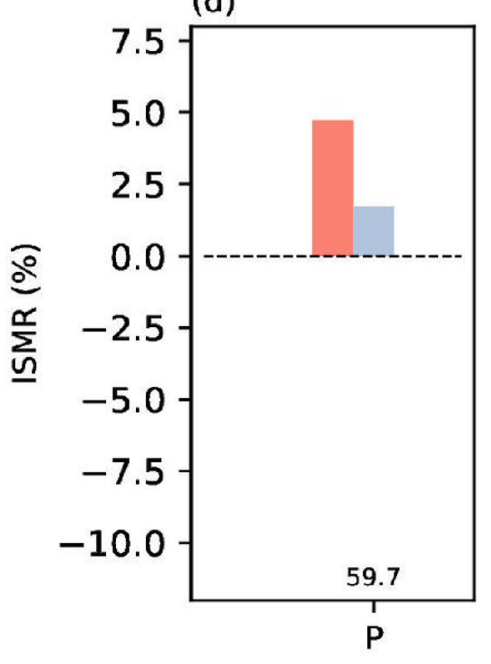

Figure 4. The teleconnection to Indian Ocean Dipole (IOD). Composite change in the anomalous surface pressure $(\mathrm{hPa})$ and vertically integrated moisture flux vector $\left(\mathrm{kgm}^{-1} \mathrm{~s}^{-1}\right)$ during (a) positive (PIOD) and (b) negative (NIOD) phases. (c) Shows the vertically integrated moisture flux anomalies and its decomposition along the four boundaries (west $\left(F_{W}\right)$, east $\left(F_{E}\right)$, south $\left(F_{S}\right)$, and north $\left(F_{N}\right)$ ) and net moisture convergence $\left(F_{\text {net }}\right)$ over region marked as ABCD in Fig. 1a, for PIOD (red) and NIOD (blue) years. The contribution to total moisture flux (solid fill) and its components: due to winds $\left(\left\langle\vec{V}^{\prime} \bar{q}\right\rangle\right)$, moisture $\left(\left\langle\vec{V} q^{\prime}\right\rangle\right)$, and eddy flux $\left(\left\langle\vec{V}^{\prime} q^{\prime}\right\rangle\right)$. (d) The corresponding change in the Indian summer monsoon rainfall (ISMR) during PIOD and NIOD. The number along $F_{n e t}$ and $\mathrm{P}$ represents the significance level at which the hypothesis that means are the same for IOD years is rejected. We regress out the impact of ENSO from all variables shown in this plot. This figure was created using NCL version 6.4.0 (https://www.ncl.ucar.edu/).

example, a subsided moisture content over Arabian Sea will lead to decreased $F_{W}$ which in turn reduces rainfall. However, the role of moisture on $F_{E}$ is not significant.

Positive vs negative Indian ocean dipole. Changes in Ps during positive Indian Ocean Dipole (PIOD) are zonally coherent north of $15^{\circ} \mathrm{N}$ over the south and east Asia, marked by a reduction in Ps from the northern Arabian Sea to western north Pacific Ocean (Fig. 4a). However, south of the equator, an east-west dipole structure is prominent, consistent with previous studies on convection during PIOD years ${ }^{9,49}$. However, most interesting is the meridionally coherent decrease in Ps from the western equatorial Indian Ocean to the northern Arabian Sea. This pattern of $P s$ anomaly north and south of the equator is due to a Matsuno-Gill type response of heating over the western equatorial Indian Ocean ${ }^{50,51}$. These result in stronger equatorial easterlies and south-westerlies over the Arabian Sea along with more substantial moisture flux toward the Indian monsoon domain (Fig. 4a). However, the anticyclonic circulation over the southern Bay of Bengal takes more moisture out of the Indian monsoon domain. We also note that this anticyclonic circulation is responsible for a robust inward moisture flux through the southern boundary $\left(F_{S}\right)$. An equivalent increase in $F_{E}$ compensates the increase in $F_{S}$ and the resulting $F_{\text {net }}$ is almost equal to $F_{W}$ (Fig. $4 \mathrm{c}$ ).

Changes in Ps during negative Indian Ocean Dipole (NIOD) years are not symmetrically opposite to that during PIOD (Fig. 4b). NIOD is characterised by a reduction in Ps over the eastern equatorial Indian Ocean. The associated increase in Ps over the western equatorial Indian Ocean is weak. However, the cyclonic circulation over the southern Bay of Bengal is of comparable intensity to the corresponding anticyclone during PIOD. As a result, moisture flux at $90^{\circ} \mathrm{E}\left(F_{E}\right)$ is of similar magnitude but opposite sign in PIOD and NIOD years (Fig. $\left.4 \mathrm{c}\right)$. But this gain in moisture during NIOD years is compensated by the outgoing flux at the southern boundary $\left(F_{S}\right)$. Previous 
(a)

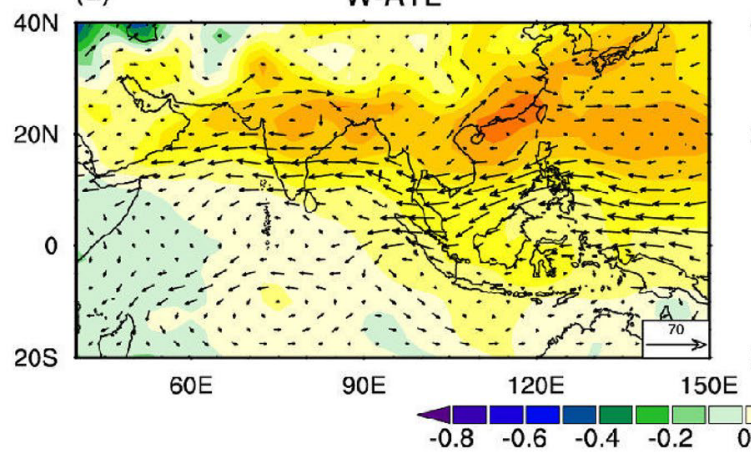

(c)

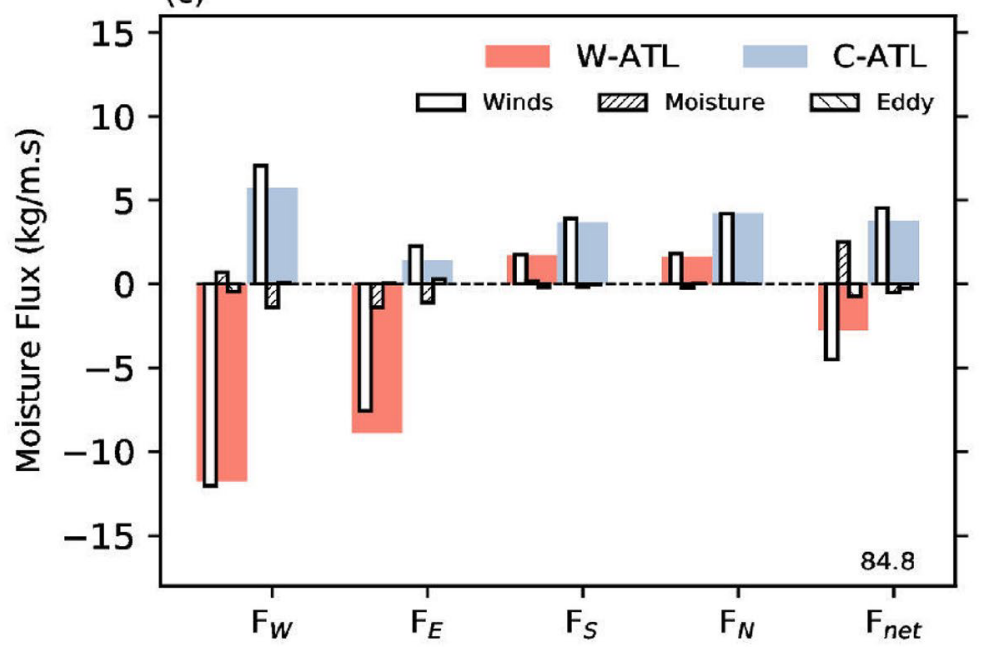

(b)

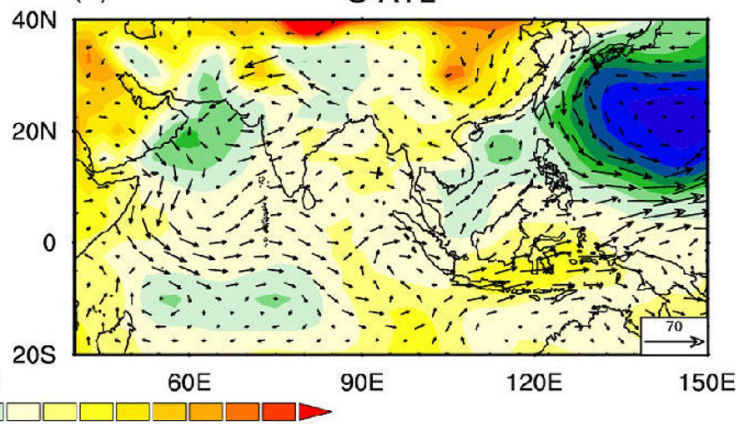

(d)

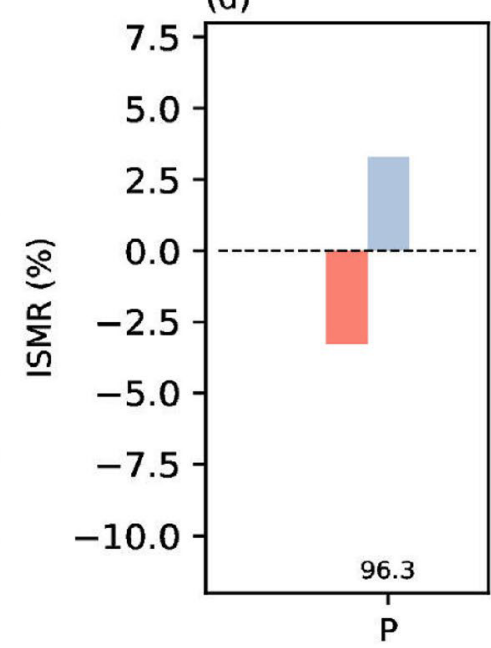

Figure 5. The teleconnection to tropical Atlantic variability (ATL). Composite change in the anomalous surface pressure (hPa) and vertically integrated moisture flux vector $\left(\mathrm{kgm}^{-1} \mathrm{~s}^{-1}\right)$ during (a) warm (W-ATL) and (b) cold (C-ATL) phases of ATL. (c) Shows the vertically integrated moisture flux anomalies and its decomposition along the four boundaries (west $\left(F_{W}\right)$, east $\left(F_{E}\right)$, south $\left(F_{S}\right)$, and north $\left.\left(F_{N}\right)\right)$ and net moisture convergence $\left(F_{\text {net }}\right)$ over region marked as ABCD in Fig. 1a, for W-ATL (red) and C-ATL (blue) years. The contribution to total moisture flux (solid fill) and its components: due to winds $\left(\left\langle\vec{V}^{\prime} \bar{q}\right\rangle\right)$, moisture $\left(\left\langle\vec{V} q^{\prime}\right\rangle\right)$, and eddy flux $\left(\left\langle\vec{V}^{\prime} q^{\prime}\right\rangle\right)$. (d) The corresponding change in the Indian summer monsoon rainfall (ISMR) during W-ATL and C-ATL. The number along $F_{n e t}$ and $\mathrm{P}$ represents the significance level at which the hypothesis that means are the same for ATL years is rejected. We regress out the impact of ENSO from all variables shown in this plot. This figure was created using NCL version 6.4.0 (https://www.ncl.ucar.edu/).

studies highlighted the importance of changes in zonal moisture flux during IOD years ${ }^{9,23}$. However, we note here that, unlike ENSO, the moisture term over the Arabian Sea $\left(\bar{u} q^{\prime}\right)$ plays a minor role in the vertically integrated moisture flux anomaly during PIOD years. Thus, a combination of moisture and winds dominates the more strong moisture flux anomalies over the Arabian Sea $\left(F_{W}\right)$ during ENSO years (Fig. 3c) than wind-only driven moisture flux anomalies during PIOD years. It is also interesting to note that although $F_{W}$ is weak during NIOD years, the moisture component dominates this observed increase in $F_{W}$. The difference in $F_{\text {net }}$ between PIOD and NIOD years (Fig. 4c) and the associated difference in ISM rainfall are not statistically significant (Fig. 4d).

Warm vs cold equatorial Atlantic ocean. The warm Atlantic events (W-ATL) show a zonally coherent increase in $P s$ over the south and east Asian monsoon domains (Fig. 5a) ${ }^{50,52}$. The zonally symmetric change in the meridional gradient in $P s$ decreases the eastward zonal moisture flux at $70^{\circ} \mathrm{E}\left(F_{W}\right)$ as well as at $90^{\circ} \mathrm{E}\left(F_{E}\right.$; Fig. $\left.5 \mathrm{c}\right)$. However, the decrease in $F_{W}$ exceeds $F_{E}$ resulting in a net reduction in zonal moisture convergence by $3 \mathrm{~kg} / \mathrm{m} / \mathrm{s}$ over the Indian monsoon domain. The meridional fluxes are being comparable and opposite in sign in terms of contribution to convergence, the net moisture flux for W-ATL decreases, resulting in a reduction of ISMR (Fig. 5d).

The impact of cold Atlantic events (C-ATL) is not opposite to that of W-ATL. Unlike for W-ATL, C-ATL associated Ps changes are negligible over south Asia (Fig. 5b). A zonally oriented decrease in Ps is observed in the subtropical Pacific Oceans indicating a reduction in the strength of the subtropical high (Supplementary Fig. 6f). However, Ps decreases over the northern Arabian Sea, resulting in a cyclonic circulation and increase in $F_{W}$ (Fig. 5 c). $F_{E}$ contribution is less as compared to $F_{W}$ during C-ATL. It can be explained through the eastward shift of anomalous low surface pressure over western North Pacific (Fig. 5b) induced due to Gill type quadrupole response of the Atlantic variability ${ }^{10}$. Therefore the response of C-ATL is weaker along the eastern boundary moisture flux $\left(F_{E}\right)$ in comparison to W-ATL. The net zonal moisture convergence for C-ATL is $4 \mathrm{~kg} / \mathrm{m} / \mathrm{s}$. The 
(a)

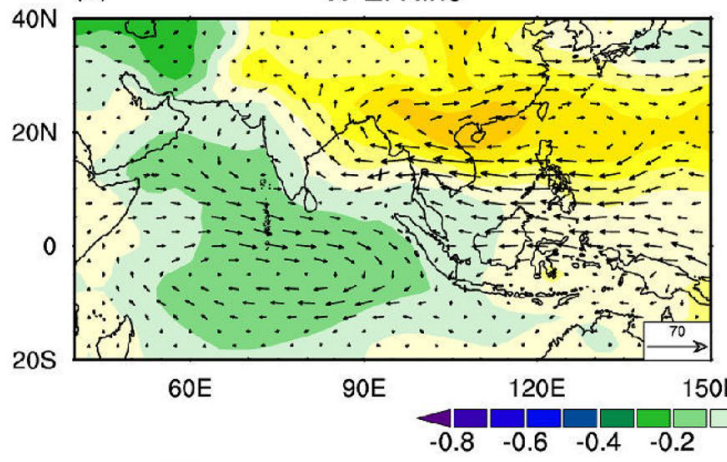

(c)

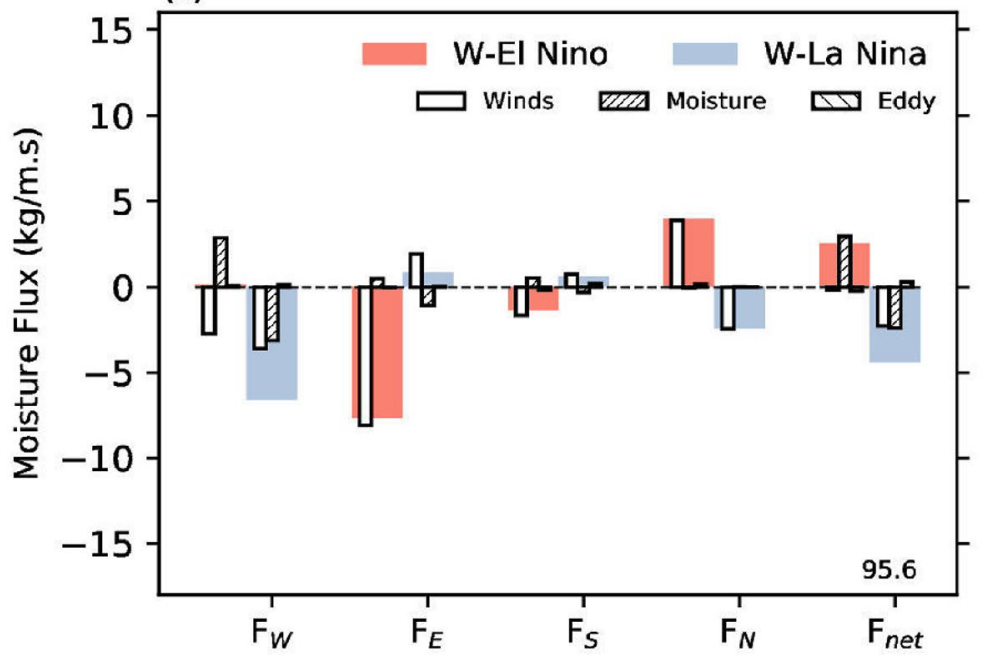

(b)

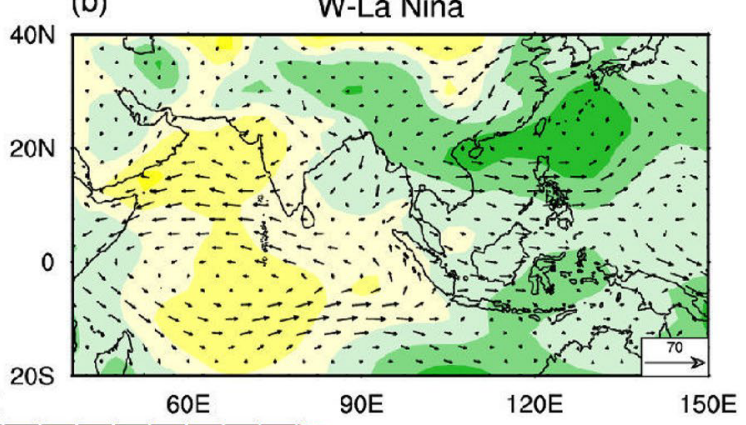

(d)

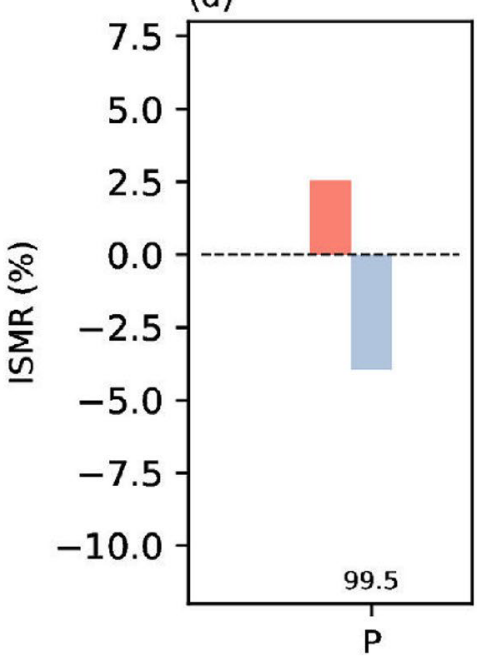

Figure 6. The teleconnection to preceding winter El Nino Southern Oscillation (W-ENSO). Composite change in the anomalous surface pressure $(\mathrm{hPa})$ and vertically integrated moisture flux vector $\left(\mathrm{kgm}^{-1} \mathrm{~s}^{-1}\right)$ during (a) winter El Nino (W-El Nino) and (b) winter La Nina (W-La Nina). (c) Shows the vertically integrated moisture flux anomalies and its decomposition along the four boundaries (west $\left(F_{W}\right)$, east $\left(F_{E}\right)$, south $\left(F_{S}\right)$, and north $\left(F_{N}\right)$ ) and net moisture convergence $\left(F_{n e t}\right)$ over region marked as ABCD in Fig. 1a, for W-El Nino (red) and W-La Nina (blue) years. The contribution to total moisture flux (solid fill) and its components: due to winds $\left(\left\langle\vec{V}^{\prime} \bar{q}\right\rangle\right)$, moisture $\left(\left\langle\vec{V} q^{\prime}\right\rangle\right)$, and eddy flux $\left(\left\langle\vec{V}^{\prime} q^{\prime}\right\rangle\right)$. (d) The corresponding change in the Indian summer monsoon rainfall (ISMR) during W-El Nino and W-La Nina. The number along $F_{\text {net }}$ and $\mathrm{P}$ represents the significance level at which the hypothesis that means are the same for W-ENSO years is rejected. We regress out the impact of ENSO from all variables shown in this plot. This figure was created using NCL version 6.4.0 (https://www.ncl. ucar.edu/).

net meridional transport of moisture is close to zero for C-ATL, resulting in an increase in net convergence and increase in ISMR (Fig. 5d). The differences in the decrease in ISMR during W-ATL and the corresponding increase during C-ATL are statistically significant at 96\% level (Fig. 5d).

It is interesting to note that the moisture contribution $\left(\bar{u} q^{\prime}\right)$ to the net flux anomaly $\left(F_{n e t}\right)$ during W-ATL years is positive, opposing a stronger negative contribution from the winds $(u / \bar{q})$. The result is a weaker $F_{\text {net }}$ compared to that would have been from wind anomalies alone. C-ATL events do not show a significant contribution to $F_{n e t}$ from the moisture component.

Preceding Winter's El Nino vs La Nina. Recent research shows that preceding winter ENSO state can provide a reliable precursor to the summer mean rainfall anomalies over India and east Asia ${ }^{11}$. Part of the above mentioned signal in ISMR could be due to ENSO transition ${ }^{53}$. However, these anomalies are asymmetric for the winter El Nino and La Nina, the latter having more impact than the former ${ }^{11}$. Figure 6 a shows that during summer months preceded by winter El Nino the Ps anomalies are tilted over the south and east Asia. Decreased Ps is observed over Southwest parts while $P$ s increases over the northeast parts of the Indian monsoon domain. As a result, the meridional gradient of $P s$ decreases over the Bay of Bengal, decreasing $F_{E}$ (Fig. 6c). This observed signature of preceding winter's ENSO in Ps anomaly over the norther West Pacific Ocean could be due to the seasonal foot-printing mechanism ${ }^{54}$. This could be one of the reason why SST of the previous winter of the northern west Pacific Ocean could be a precursor of the following summer monsoon rainfall over India ${ }^{55}$.

In contrary to winter El Nino, the meridional gradient decreases along the western sides of India, decreasing $F_{W}$ during years preceded by winter La Nina (Fig. $6 \mathrm{~b}$ ). This change in gradient in Ps reduces the $F_{\text {net }}$. Overall, 
the increase (decrease) in net moisture convergence enhances (reduces) rainfall for years preceded by winter El Nino (La Nina) (Fig. 6d). However, while incoming zonal flux differences $\left(F_{W}\right)$ dominate W-La Nina, outgoing zonal flux $\left(F_{E}\right)$ dominates the W-El Nino years.

We also note that the contribution from the moisture term (Eqn 1) is significant (about 50\%) for $F_{W}$ and $F_{\text {net }}$ during W-La Nina years. The moisture contributes almost the entire change in $F_{\text {net }}$ during W-El Nino years (Fig. 6c). It underlines the importance of moisture anomaly and wind anomalies for the years preceded by winter ENSO conditions. A parallel can be made here with the summer ENSO years (Fig. 3c) and conclude that impact of summer as well as preceding winter ENSO on moisture convergence over the Indian region is both through dynamic (wind) and thermodynamic (moisture) effects.

Summary of tropical teleconnection. We have seen that ENSO impacts Ps surrounding the Indian region by changing the large-scale patterns. However, the intensity of changes is not spatially coherent (Supplementary Fig. 7). While increase (decrease) in Ps with El Nino (La Nina) is most prominent over Ps1, Ps2, and Ps4, the ENSO response is weak over Ps3. The intensity of Ps1-Ps2 decreases (increases) during El Nino (La Nina; Supplementary Fig. 8a), resulting in a reduction (growth) in $F_{W}$ (Supplementary Fig. 8b). On the other hand, the impact of ENSO along the eastern boundary (Ps3-Ps4) and the corresponding moisture flux $\left(F_{E}\right)$ is opposite to that along the western edge.

The IOD changes Ps 1 and Ps 2 with the same intensity (a positive IOD decrease Ps over these regions and vice-versa). However, the impact of IOD over Ps3 and Ps4 are opposite. It suggests weak changes in moisture flux along the western boundary (Supplementary Fig. 8b) but a substantial increase in the outgoing moisture flux along the eastern edge.

The ATL SST forcing, on the other hand, changes the meridional pressure gradient along the western boundary $(P s 1-P s 2)$. However, the change in the gradient along the eastern part is small. The corresponding moisture flux responses follow this pressure gradient.

Finally, the impact of preceding winter's ENSO state is at the eastern parts of the Indian monsoon domain, changing $P s$ mainly over $P s 3$. Changes in the moisture flux follow the $P s$ gradient, with weak changes for $F_{W}$ and significant changes for $F_{E}$ and $F_{S}$.

Drought vs flood during ENSO vs Non-ENSO years. How do the Ps and moisture fluxes contribute to droughts and floods of ISMR? In particular, we are interested in the relative contribution of the different flux components in driving droughts and floods over India during ENSO and non-ENSO years. To do that, we start with identifying droughts (ISMR less than $-10 \%$ of climatology) and floods (ISMR greater than $+10 \%$ of its climatology). We then subdivide these years based on summer ENSO conditions. If drought occurred during summer El Nino (non-El Nino) we would term the year as ENSO (non-ENSO) drought. Similarly, if flood occurred during summer La Nina (non-La Nina), we term the year as ENSO (non-ENSO) flood (Supplementary Note 2 Table 2).

A meridional increase in Ps from the western equatorial Indian Ocean to the northern Arabian Sea characterises ENSO droughts (Fig. 7a). On the eastern side, Ps decreases from the eastern equatorial Indian Ocean toward the north. This results in a decrease in $F_{W}$ and increases in $F_{E}$ with a net reduction in the net zonal moisture flux (Fig. 7c). Non-ENSO droughts are associated by a gradient of $P s$ along the western boundary of India similar to that for ENSO, but with a more substantial magnitude up to about $15^{\circ} \mathrm{N}$. The resulting decrease in $F_{W}$ exceeds that for the ENSO case. However, the change in meridional Ps gradient and related change in moisture flux along the eastern boundary is weak during the Non-ENSO droughts (Fig. 7a).

During flood years associated with ENSO (La Nina), the climatological Ps gradient (Fig. 1a) steepens further from south to north over the Arabian Sea (Fig. 7b). This facilitates more moisture to enter the Indian region driven by stronger lower tropospheric winds. However, for non-ENSO floods, this steepening of Ps gradient is more significant than for ENSO. This is reflected in the more substantial incoming (westward) moisture flux for non-ENSO floods than ENSO floods (Fig. 7d). At the eastern side of the Indian region, meridional Ps gradients weaken during ENSO floods resulting in a decrease in outgoing moisture flux $\left(F_{E}\right)$. On the other hand, in nonENSO floods, the meridional Ps gradient steepens at the eastern side of the Indian region, albeit with a lower magnitude than over Arabian Sea. As a result, the increased outgoing $F_{E}$ during non-ENSO years is weaker than the increased incoming $F_{W}$, and the net zonal moisture convergence is positive.

\section{Discussion}

We aimed to develop a physically-based theory for the interannual variations of the ISMR that, at the same time, can be used to explain the relative impacts of different tropical climate phenomena. We used the fact that net moisture convergence (and hence the total column precipitable water vapour) is highly correlated with rainfall over a season. We showed that relative change in the moisture fluxes along the boundaries of the Indian monsoon region determines by year-to-year variations in the moisture convergence. These flux anomalies are functions of perturbation winds and moisture. We showed that meridional $P s$ gradients drive the interannual variations of lower-tropospheric zonal winds. The winds, in turn, carry a significant fraction of moisture in and out of the Indian region. The finding led us to define teleconnection mechanisms through which various tropical climate patterns control Ps surrounding the Indian region.

Although the positive (heating) and negative (cooling) phases of all significant tropical SST patterns are not significantly different from Gaussian distribution (Supplementary Fig. 9), their response to the perturbation pressure around the globe, especially over the south and east Asian monsoon region, is asymmetric (Supplementary Fig. 6). The resulting reaction to vertically integrated moisture transport is also asymmetric. The decrease (increase) in ISMR by $10 \%$ (5\%) during El Nino (La Nina) is due to a more robust (weaker) decrease (enhancement) in inward moisture flux through the western boundary. During El Nino, the reduction mentioned above in 
(a)

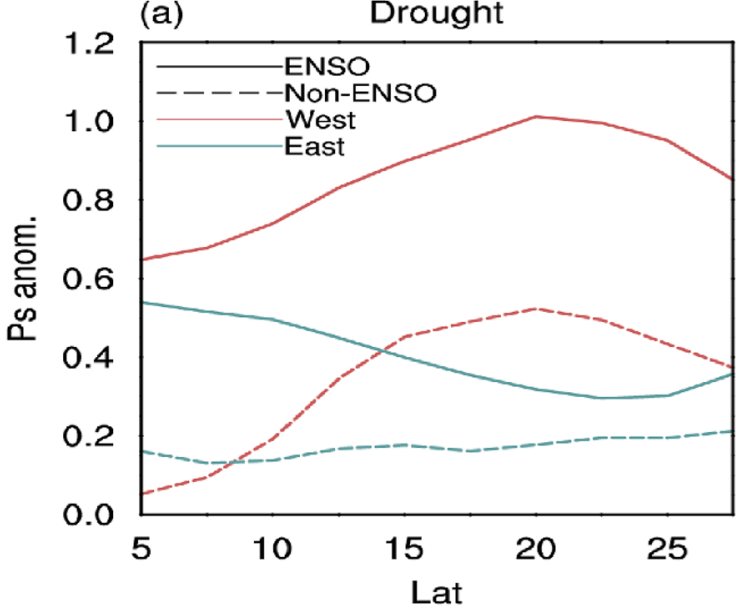

(c) Drought

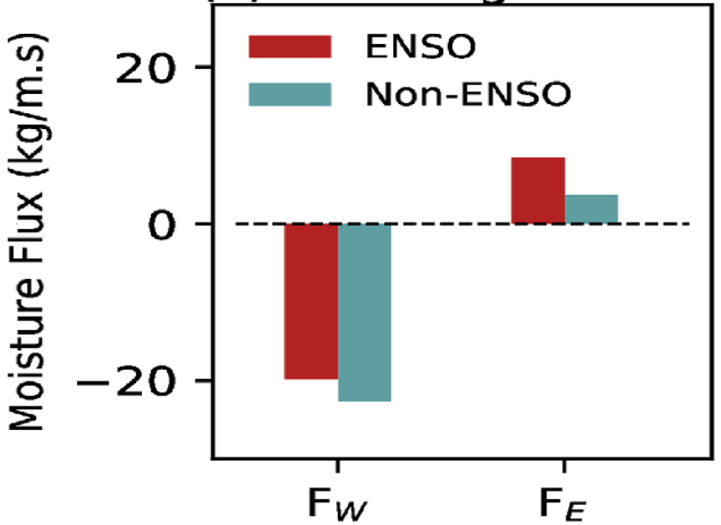

(b)

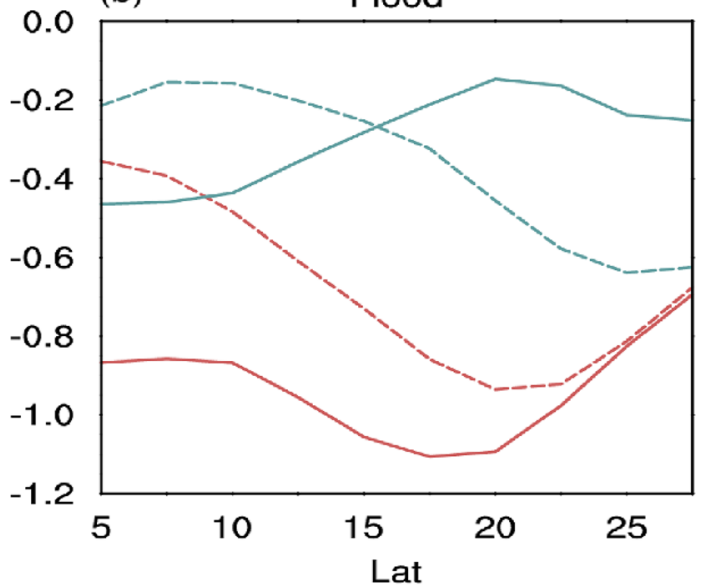

(d) Flood

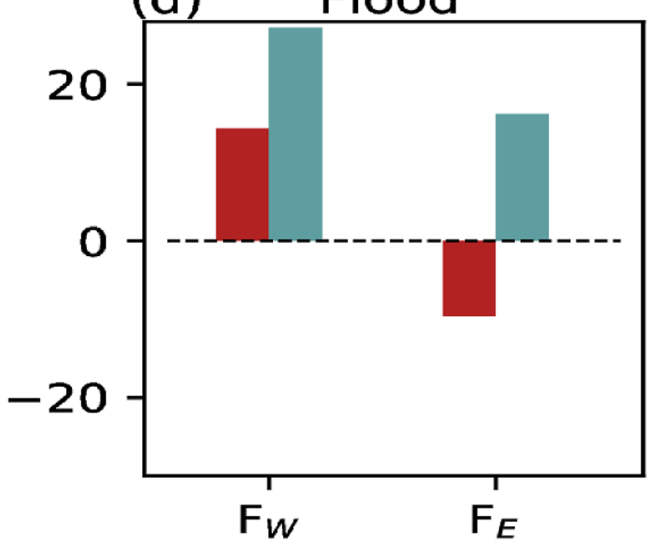

Figure 7. Drought and flood during ENSO and Non-ENSO years. The latitudinal profile of surface pressure variation (hPa) along the western (red) and eastern (blue) boundary for ENSO (solid) and Non-ENSO (dashed) related (a) drought and (b) flood, respectively. (c, d) Shows the relative contribution of zonal moisture fluxes $\left(F_{W}\right.$ and $\left.F_{E}\right)$ associated with drought and flood over Indian region during ENSO (red) and Non-ENSO (blue) years. This figure was created using NCL version 6.4.0 (https://www.ncl.ucar.edu/).

the zonal moisture flux over the Arabian Sea is contributed by changes in the winds and moisture. We noticed a strong circulation anomaly over south Asia during PIOD years but without any significant moisture convergence. The NIOD years are characterised by weak pressure anomalies apart from the eastern equatorial Indian Ocean. Changes in Ps and circulation during W-ATL are stronger than C-ATL events. However, an anomalous cyclonic circulation over the northern Arabian Sea and north-Western Indian region resulted in more substantial inward moisture flux and increased ISMR during C-ATL years. The impacts of preceding winter ENSO events in terms of $P$ s changes over the south and east Asia is somewhat opposite to that for summer ENSO events, albeit with weaker magnitudes. However, the impact of preceding winter's ENSO on Ps is most robust over the north-eastern parts of the Indian summer monsoon.

When put together, ENSO-driven extremes of ISMR (droughts and floods) are contributed by an opposite sign of change in meridional Ps gradients over the Arabian Sea and the Bay of Bengal (Fig. 8a). However, nonENSO-driven seasonal extremes show a similar sign in meridional Ps gradient over the Arabian Sea and the Bay of Bengal (Fig. 8b). In the non-ENSO years, extremes occur because of the relative change in the Ps gradient and moisture flux on the west and east sides of the Indian monsoon region. In summary, ENSO-driven extremes occur due to asymmetric change in Ps both in zonal and meridional directions. But non-ENSO driven extremes occur due to zonal variation of zonally symmetric changes in $P$ s.

In this study, we have not addressed the possible role of extra-tropical SST variability on ISMR, shown to be important by several authors ${ }^{55-58}$. An preliminary set of analysis (Supplementary Figs. 10, 11, 12) investigating the role of north Pacific Ocean SST on surface pressure surrounding India and associated change in ISMR confirms some of the findings cited above. We have also not investigated the reasons behind the depicted asymmetric response of $P s$ to different tropical climate patterns. However, preliminary analysis showed that disparate spatial distribution of heat source and sinks ${ }^{59}$ (not shown), and the associated moist convection, could lead to different Gill responses in Ps and winds.

In summary, we proposed a mechanism for the interannual variations of seasonal mean summer monsoon rainfall over India based on moisture budget. This mechanism physically links the pressure perturbation pattern and circulation to the available moisture, a quantity directly related to moist convection. We showed how 


\section{(a) ENSO : Drought minus Flood}

\section{(b)Non-ENSO : Drought minus Flood}

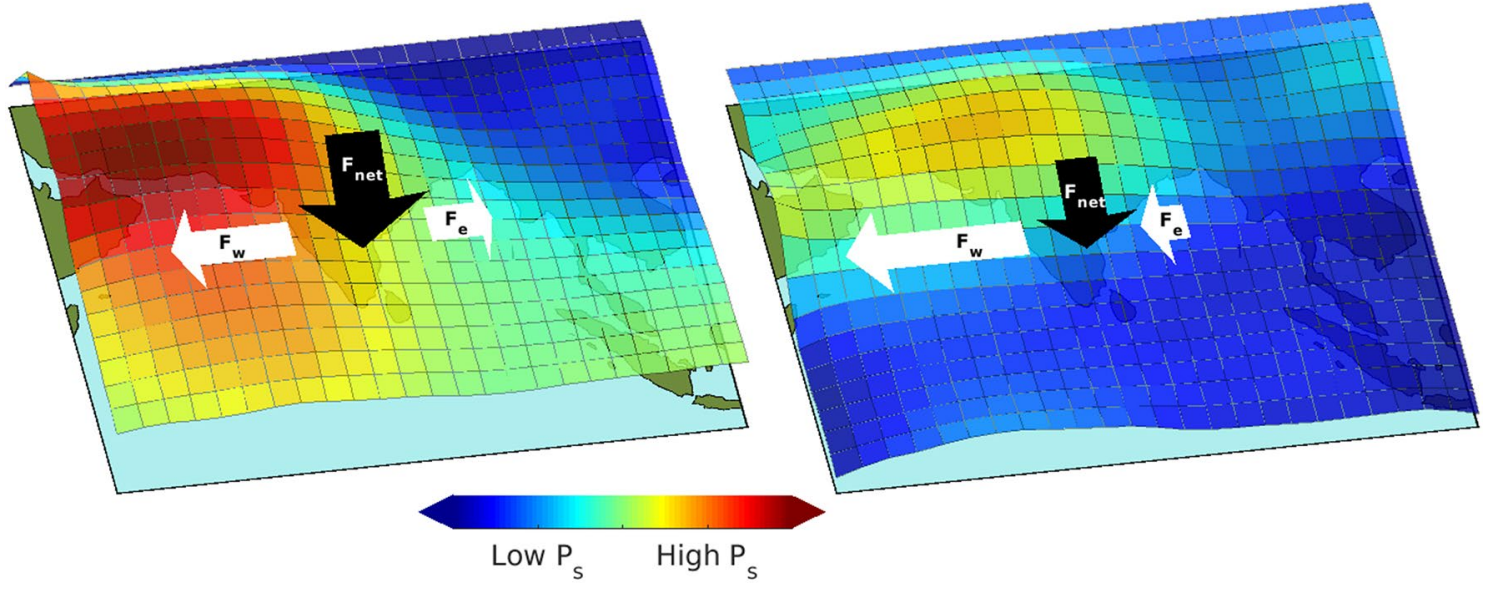

Figure 8. Schematic showing variations in surface pressure surrounding the Indian monsoon region due to (a) ENSO and (b) Non-ENSO forcing leading to Indian summer monsoon rainfall extremes (drought and flood). The horizontal arrows represent the zonal moisture flux at the western $\left(F_{W}\right)$ and eastern $\left(F_{E}\right)$ boundaries. The vertical arrow indicates the net moisture convergence $\left(F_{n e t}\right)$ over the Indian domain. This figure was created using MATLAB version R2020b (https://in.mathworks.com/).

different tropical climate patterns modulate these parameters. In reality, often more than once forcing appear simultaneously. While one could linearly separate their influences, for example, using SST-based indices, the actual superposition of individual effects could be non-linear. Moreover, recent researches indicate coupled interaction and evolution of tropical ocean basins ${ }^{60}$. Thus, it is difficult to completely separate out the impact of one forcing from the other on ISM. However, our study illustrates the signature of four major tropical climate patterns on monsoon teleconnection using a common mechanism. This theory would be helpful to test the teleconnection mechanisms simulated by general circulation models.

\section{Methods}

Data. We use monthly mean gridded rainfall data of the Indian Meteorological Department (IMD) rain gauge network at a spatial resolution of $1^{\circ} \times 1^{\circ}$ from $1948-2015^{61}$. The atmospheric parameters are taken from National Center for Environmental Prediction/National Center for Atmospheric Research (NCEP/NCAR) reanalysis product with a spatial resolution of $2.5^{\circ} \times 2.5^{\circ 62}$. We also use Extended reconstructed sea surface temperature (ER-SST) version 5 data for the same period ${ }^{63}$. All variables considered are departures from the monthly mean annual cycle and detrended over the 68 years.

Parameter/index calculation. In this study, we define Indian summer monsoon rainfall (ISMR) as JuneSeptember (JJAS) area-averaged rainfall over the Indian land region $\left(7.5^{\circ}-27.5^{\circ} \mathrm{N}, 70^{\circ}-90^{\circ} \mathrm{E}\right)^{64}$. Here, we consider four dominant tropical SST forcing, namely ENSO, IOD, ATL, and preceding winter ENSO (W-ENSO). The ENSO and preceding winter ENSO define as area-averaged SST anomaly over Nino 3.4 region $\left(5^{\circ} \mathrm{S}-5^{\circ} \mathrm{N}\right.$, $\left.170^{\circ} \mathrm{W}-120^{\circ} \mathrm{W}\right)$ during boreal summer (JJAS) and the preceding winter (December-February; DJF), respectively. If SST is less than $-0.5^{\circ} \mathrm{C}$ (greater than $+0.5^{\circ} \mathrm{C}$ ), we identify it as La Nina or W-La Nina (El Nino or $\mathrm{W}$-El Nino $)^{11}$. The IOD index is the difference in SST anomalies between the western $\left(10^{\circ} \mathrm{S}-10^{\circ} \mathrm{N}, 50^{\circ}-70^{\circ} \mathrm{E}\right)$ and eastern $\left(10^{\circ} \mathrm{S}\right.$-equator, $\left.90^{\circ}-110^{\circ} \mathrm{E}\right)$ equatorial Indian Ocean ${ }^{65}$. We calculate ATL as domain averaged SST anomalies bounded by $20^{\circ} \mathrm{S}$ to the equator and $30^{\circ} \mathrm{W}$ to $20^{\circ} \mathrm{E}^{10,34}$. The positive (negative) phases of IOD and ATL consider when the JJAS averaged values exceeds one (less than minus one) standard deviation. List of these years from 1948 through 2015 are provided in Supplementary Note 2 Table 1.

Regress out ENSO component. The ENSO exerts a strong influence on the Indian summer monsoon. To quantify the effect of other tropical climate patterns independent of ENSO, we remove the linear dependence of ENSO. We calculate residual time series of all variables (like ISMR, $P s$, moisture flux).

$$
\begin{gathered}
V a r_{r e s}(t)=\operatorname{Var}(t)-\operatorname{Var}_{E N S O}(t), \\
\operatorname{Var}_{E N S O}(t)=b \operatorname{Nino34}(t) .
\end{gathered}
$$

where $b$ in Eq. 3 is obtained using least-squares linear fit. We use the above concept to quantify the role of other climate forcings such as Indian Ocean dipole, Atlantic Nino, and preceding winter ENSO in modulating Indian monsoon, as shown in Figs. 4, 5, and 6. We note here that, we did not regress out the impact of ENSO on SST representing IOD, ATL or W-ENSO as those parameters have there standard definition this way. 
Flux computation. We compute moisture flux over the Indian domain $\left(7.5^{\circ}-27.5^{\circ} \mathrm{N}, 70^{\circ}-90^{\circ} \mathrm{E}\right)$ using the moisture budget equation shown in equation 4 . It states that the net change in moisture convergence $\left(F_{\text {net }}\right)$ over the given domain is equal to the difference in precipitation $(\mathrm{P})$ and evaporation $(\mathrm{E})$ and change in total column water vapour $\left(P_{\text {wat }}\right)$. On interannual timescale, the change in evaporation and $P_{\text {wat }}$ are small as compared to precipitation; therefore, it is justifiable to say that precipitation is highly governed by net moisture convergence over that area (Fig. 1b).

$$
\begin{gathered}
\frac{1}{A}\left(F_{W}-F_{E}+F_{S}-F_{N}\right)=\bar{P}-\bar{E}+\frac{\partial P_{w a t}}{\partial t}, \\
\frac{1}{A}\left(F_{N e t}\right)=\bar{P}-\bar{E}+\frac{\partial P_{w a t}}{\partial t}
\end{gathered}
$$

where, $F_{W}, F_{E}, F_{S}$, and $F_{N}$ are vertically integrated moisture fluxes at the western, eastern, southern, and northern boundaries, respectively. We calculate it using the following formulae:

$$
F=\int_{P_{s f c}}^{P_{t o p}}(q \cdot u) \mathrm{d} p / g
$$

where $\mathrm{q}$ and $\mathrm{u}$ are specific humidity $(\mathrm{kg} / \mathrm{kg})$ and wind vector $(\mathrm{m} / \mathrm{sec})$ at the respective boundaries. $P_{s f c}$ and $P_{\text {top }}$ represent the pressure at the surface and top of the atmosphere. Here, $P_{\text {top }}$ is taken as $100 \mathrm{hPa}$.

Statistical significance test. We used a student's t-test to access the level of confidence at which two distributions are different. Consider $A$ and $B$ are two ensembles with population mean $\mu_{A}$ and $\mu_{B}$ respectively. The null hypothesis states that

$$
\left|\mu_{A}-\mu_{B}\right|=0
$$

and the alternate hypothesis is

$$
\left|\mu_{A}-\mu_{B}\right| \neq 0
$$

From the ensembles estimate of mean and variance, we reject null hypothesis at $95 \%$ significance level if

$$
\left|t_{s}\right|=\frac{|\bar{A}-\bar{B}|}{\sqrt{\frac{\left(n_{A}-1\right) s_{A}^{2}+\left(n_{B}-1\right) s_{B}^{2}}{n_{A}+n_{B}-2} \times \frac{n_{A}+n_{B}}{n_{A} n_{B}}}}>t_{0.05, n_{A}+n_{B}-2}
$$

where $\bar{A}$ and $\bar{B}$ are the sample means and $s_{A}$ and $s_{B}$ are standard deviations of the corresponding ensembles, and $n_{A}, n_{B}$ are number of members within $A$ and $B$, respectively.

Received: 8 August 2021; Accepted: 2 November 2021

Published online: 19 November 2021

\section{References}

1. Mooley, D. \& Parthasarathy, B. Fluctuations in all-India summer monsoon rainfall during 1871-1978. Climatic Change 6, 287-301 (1984).

2. Gadgil, S. The Indian monsoon and its variability. Ann. Rev. Earth Planet. Sci. 31, 429-467 (2003).

3. Meehl, G. A. The south Asian monsoon and the tropospheric biennial oscillation. J. Climate 10, 1921-1943 (1997).

4. Kripalani, R. H. \& Kulkarni, A. Climatic impact of El Niño/La Niña on the Indian monsoon: A new perspective. Weather 52, 39-46. https://doi.org/10.1002/j.1477-8696.1997.tb06267.x (1997).

5. Karmakar, N., Chakraborty, A. \& Nanjundiah, R. S. Influence of global sea-surface temperature on ultra-low-frequency variability in Indian summer monsoon rainfall. Quart. J. Royal Meteorol. Soc. 146, 904-921 (2020).

6. Goswami, B. Interannual variations of Indian summer monsoon in a GCM: External conditions versus internal feedbacks. J. Climate 11, 501-522 (1998).

7. Huang, X. et al. The recent decline and recovery of Indian summer monsoon rainfall: Relative roles of external forcing and internal variability. J. Climate 33, 5035-5060 (2020).

8. Kumar, K. K., Rajagopalan, B. \& Cane, M. A. On the weakening relationship between the Indian monsoon and ENSO. Science 284, 2156-2159 (1999).

9. Ashok, K., Guan, Z. \& Yamagata, T. Impact of the Indian Ocean dipole on the relationship between the Indian monsoon rainfall and ENSO. Geophys. Res. Lett. 28, 4499-4502 (2001).

10. Kucharski, F., Bracco, A., Yoo, J. \& Molteni, F. Low-frequency variability of the Indian monsoon-ENSO relationship and the tropical Atlantic: The weakening of the 1980s and 1990s. J. Climate 20, 4255-4266 (2007).

11. Chakraborty, A. Preceding winter La Niña reduces Indian summer monsoon rainfall. Environ. Res. Lett. 13, 054030 (2018)

12. Walker, G. \& Bliss, E. World weather V. Memoirs Royal Meteorol. Soc. 4, 53-84 (1932).

13. Sikka, D. Some aspects of the large scale fluctuations of summer monsoon rainfall over India in relation to fluctuations in the planetary and regional scale circulation parameters. Proc. Indian Acad. Sci. Earth Planet. Sci. 89, 179-195 (1980).

14. Goswami, B. N. \& Xavier, P. K. ENSO control on the south Asian monsoon through the length of the rainy season. Geophys. Res. Lett. 32 (2005).

15. Shaman, J. \& Tziperman, E. Summertime ENSO-North African-Asian jet teleconnection and implications for the Indian monsoons. Geophys. Res. Lett. 34 (2007).

16. Torrence, C. \& Webster, P. J. Interdecadal changes in the ENSO-monsoon system. J. Climate 12, 2679-2690 (1999).

17. Krishnamurthy, V. \& Goswami, B. N. Indian monsoon-ENSO relationship on interdecadal timescale. J. Climate 13, 579-595 (2000). 
18. Srivastava, G., Chakraborty, A. \& Nanjundiah, R. S. Multidecadal see-saw of the impact of ENSO on Indian and West African summer monsoon rainfall. Climate Dyn. 52, 6633-6649 (2019).

19. Azad, S. \& Rajeevan, M. Possible shift in the ENSO-Indian monsoon rainfall relationship under future global warming. Sci. Rep. 6, 1-6 (2016).

20. Fan, F. et al. Revisiting the relationship between the South Asian summer monsoon drought and El Niño warming pattern. Atmosph. Sci. Lett. 18, 175-182 (2017).

21. Monahan, A. H. \& Dai, A. The spatial and temporal structure of ENSO nonlinearity. J. Climate 17, 3026-3036 (2004).

22. Hoerling, M. P., Kumar, A. \& Zhong, M. . El. Niño, La Niña, and the nonlinearity of their teleconnections. J. Climate 10, 1769-1786 (1997).

23. Behera, S., Krishnan, R. \& Yamagata, T. Unusual ocean-atmosphere conditions in the tropical Indian Ocean during 1994. Geophys. Res. Lett. 26, 3001-3004 (1999).

24. Annamalai, H. Moist dynamical linkage between the equatorial Indian Ocean and the South Asian monsoon trough. J. Atmosph. Sci. 67, 589-610 (2010).

25. Cherchi, A. et al. Indian ocean dipole influence on indian summer monsoon and enso: A review. Indian Summer Monsoon Variability 157-182 (2021).

26. Ajayamohan, R., Rao, S. A. \& Yamagata, T. Influence of Indian ocean dipole on poleward propagation of boreal summer intraseasonal oscillations. J. Climate 21, 5437-5454 (2008).

27. Yang, J., Liu, Q., Xie, S.-P., Liu, Z. \& Wu, L. Impact of the indian ocean sst basin mode on the asian summer monsoon. Geophys. Res. Lett. 34 (2007).

28. Terao, T. et al. Impacts of rapid warm-To-Cold ENSO transitions on summer monsoon rainfall over the northeastern Indian subcontinent. J. Meteorol. Soc. Jpn. Ser. II(91), 1-21. https://doi.org/10.2151/jmsj.2013-101 (2013).

29. Zhou, L., Murtugudde, R., Chen, D. \& Tang, Y. Seasonal and interannual variabilities of the central Indian ocean mode. J. Climate 30, 6505-6520 (2017).

30. Xie, S.-P. et al. Indian ocean capacitor effect on Indo-Western pacific climate during the summer following el niño. J. Climate 22, 730-747 (2009).

31. Yadav, R. K., Srinivas, G. \& Chowdary, J. S. Atlantic niño modulation of the Indian summer monsoon through Asian jet. Npj Climate Atmosph. Sci. 1, 1-11 (2018).

32. Pottapinjara, V., Girishkumar, M., Sivareddy, S., Ravichandran, M. \& Murtugudde, R. Relation between the upper ocean heat content in the equatorial Atlantic during boreal spring and the Indian monsoon rainfall during june-september. Int. J. Climatol. 36, 2469-2480 (2016).

33. Sabeerali, C., Ajayamohan, R., Bangalath, H. K. \& Chen, N. Atlantic zonal mode: An emerging source of Indian summer monsoon variability in a warming world. Geophys. Res. Lett. 46, 4460-4467 (2019).

34. Kucharski, F., Bracco, A., Yoo, J. \& Molteni, F. Atlantic forced component of the Indian monsoon interannual variability. Geophys. Res. Lett. 35 (2008).

35. Shukla, J. \& Paolino, D. A. The Southern oscillation and long-range forecasting of the summer monsoon rainfall over India. Monthly Weather Rev. 111, 1830-1837 (1983).

36. Kawamura, R. Climatic variations in relation to large-scale air-sea interaction. J. Geography (Chigaku Zasshi) 117, 1063-1076. https://doi.org/10.5026/jgeography.117.1063 (2008).

37. Wu, R. \& Wang, B. A contrast of the east Asian summer monsoon-ENSO relationship between $1962-77$ and 1978-93*. J. Climate $15,3266-3279(2002)$.

38. Jalihal, C., Srinivasan, J. \& Chakraborty, A. Modulation of Indian monsoon by water vapor and cloud feedback over the past 22,000 years. Nat. Commun. 10, 1-8 (2019).

39. Srinivasan, J. A Simple Thermodynamic Model for SeasonalVariation of Monsoon Rainfall. Current Science. 80(1), 73-77. http:// www.jstor.org/stable/24105558 (2001).

40. Srinivasan, J. Diagnostic study of errors in the simulation of tropical continental precipitation in general circulation models. Ann. Geophys. 21, 1197-1207 (2003).

41. Anjaneyalu, T. S. S. On the estimates of heat and moisture over the Indian monsoon trough zone. Tellus 21, 64-75 (1969).

42. Rao, Y. Southwest monsoon, IMD. Monograph No. Synoptic Meteorology-1/76 (1976).

43. Krishnamurti, T. Observational aspects of summer monsoon. Monsoon Meteorol. 3-25 (1987).

44. Chakraborty, A. \& Agrawal, S. Role of west Asian surface pressure in summer monsoon onset over central India. Environ. Res. Lett. 12, 074002 (2017).

45. Samson, G. et al. Roles of land surface albedo and horizontal resolution on the Indian summer monsoon biases in a coupled ocean-atmosphere tropical-channel model. Climate Dyn. 48, 1571-1594 (2017).

46. Godbole, R. \& Shukla, J. Global analysis of January and July sea level pressure. NAGA Technical Memo 82097 (1981).

47. Zhang, Y., Wallace, J. M. \& Battisti, D. S. ENSO-like interdecadal variability: 1900-93. J. Climate 10, 1004-1020 (1997).

48. Seager, R., Naik, N. \& Vecchi, G. A. Thermodynamic and dynamic mechanisms for large-scale changes in the hydrological cycle in response to global warming. J. Climate 23, 4651-4668 (2010).

49. Gadgil, S., Vinayachandran, P. \& Francis, P. Droughts of the Indian summer monsoon: Role of clouds over the Indian Ocean. Current Sci. 1713-1719 (2003).

50. Kucharski, F. et al. A Gill-Matsuno-type mechanism explains the tropical Atlantic influence on African and Indian monsoon rainfall. Quarterly J. Royal Meteorol. Soc. A J. Atmosph. Sci. Appl. Meteorol. Phys. Oceanogr. 135, 569-579 (2009).

51. Wang, C., Kucharski, F., Barimalala, R. \& Bracco, A. Teleconnections of the tropical Atlantic to the tropical Indian and Pacific Oceans: A review of recent findings. Meteorologische Zeitschrift 18, 445-454 (2009).

52. Barimalala, R., Bracco, A. \& Kucharski, F. The representation of the South Tropical Atlantic teleconnection to the Indian Ocean in the AR4 coupled models. Climate Dyn. 38, 1147-1166 (2012).

53. Terray, P. \& Dominiak, S. Indian ocean sea surface temperature and el niño-southern oscillation: A new perspective. J. Climate 18, 1351-1368 (2005).

54. Vimont, D. J., Wallace, J. M. \& Battisti, D. S. The seasonal footprinting mechanism in the Pacific: Implications for ENSO. J. Climate 16, 2668-2675 (2003).

55. Peings, Y., Douville, H. \& Terray, P. Extended winter Pacific North America oscillation as a precursor of the Indian summer monsoon rainfall. Geophys. Res. Lett. 36, 1. https://doi.org/10.1029/2009gl038453 (2009).

56. Krishnamurthy, L. \& Krishnamurthy, V. Influence of pdo on south Asian summer monsoon and monsoon-Enso relation. Climate Dyn. 42, 2397-2410. https://doi.org/10.1007/s00382-013-1856-z (2014).

57. Chattopadhyay, R. et al. Influence of extratropical sea-surface temperature on the Indian summer monsoon: An unexplored source of seasonal predictability. Quarterly J. Royal Meteorol. Soc. 141, 2760-2775 (2015).

58. Chakraborty, A. Zonally symmetric vs asymmetric north pacific ocean sea surface temperature influence on Indian summer monsoon through modulation of upper tropospheric circulation. MAUSAM 70, 753-766 (2019).

59. Yanai, M., Esbensen, S. \& Chu, J.-H. Determination of bulk properties of tropical cloud clusters from large-scale heat and moisture budgets. J. Atmosph. Sci. 30, 611-627 (1973).

60. Cai, W. et al. Pantropical climate interactions. Science 363, eaav4236. https://doi.org/10.1126/science.aav4236 (2019). 
61. Rajeevan, M., Bhate, J., Kale, J. \& Lal, B. High resolution daily gridded rainfall data for the indian region: Analysis of break and active monsoon spells. Current Sci. 296-306 (2006).

62. Kalnay, E. et al. The ncep/ncar 40-year reanalysis project. Bull. Am. Meteorol. Soc. 77, 437-472 (1996).

63. Huang, B. et al. Noaa extended reconstructed sea surface temperature (ersst), version 5. NOAA Natl. Centers Environ. Inf. 30, 8179-8205 (2017).

64. Parthasarathy, B., Munot, A. \& Kothawale, D. All-India monthly and seasonal rainfall series: 1871-1993. Theor. Appl. Climatol. 49, 217-224 (1994).

65. Saji, N., Goswami, B. N., Vinayachandran, P. \& Yamagata, T. A dipole mode in the tropical Indian Ocean. Nature 401, 360-363 (1999).

\section{Acknowledgements}

AC acknowledges National Monsoon Mission, Ministry of Earth Sciences, Govt of India for funding. This work was benefited from discussions with J. Srinivasan, and analysis support by A. Paleri.

\section{Author contributions}

A.C. conceived the idea. P.S. did the analysis. Both authors interpreted the results and reviewed the manuscript.

\section{Competing interests}

The authors declare no competing interests.

\section{Additional information}

Supplementary Information The online version contains supplementary material available at https://doi.org/ 10.1038/s41598-021-01758-6.

Correspondence and requests for materials should be addressed to A.C.

Reprints and permissions information is available at www.nature.com/reprints.

Publisher's note Springer Nature remains neutral with regard to jurisdictional claims in published maps and institutional affiliations.

(c) (i) Open Access This article is licensed under a Creative Commons Attribution 4.0 International

License, which permits use, sharing, adaptation, distribution and reproduction in any medium or format, as long as you give appropriate credit to the original author(s) and the source, provide a link to the Creative Commons licence, and indicate if changes were made. The images or other third party material in this article are included in the article's Creative Commons licence, unless indicated otherwise in a credit line to the material. If material is not included in the article's Creative Commons licence and your intended use is not permitted by statutory regulation or exceeds the permitted use, you will need to obtain permission directly from the copyright holder. To view a copy of this licence, visit http://creativecommons.org/licenses/by/4.0/.

(C) The Author(s) 2021 